\section{What red means in waste management}

When considering 'red' in the best practice waste management colour coding system, here's what you need to know:

- 'Red' is the colour used to code anatomical waste

- Red waste can be hazardous or non-hazardous and includes any waste generated from the body

- Examples for this waste stream include body parts (excluding extracted teeth), blood bags, blood preserves and animal parts.

For obvious reasons, few dental practices will generate any 'red' waste, but it remains

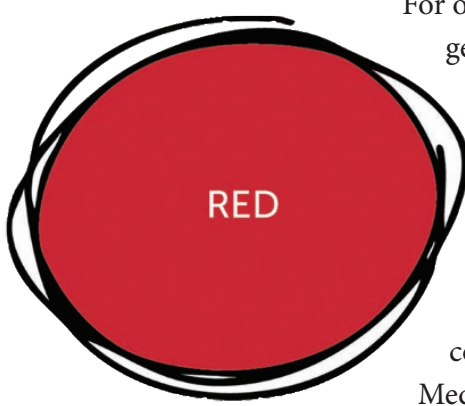
important to know what it means in order to complete the colour code.

Once waste containers (coded any colour) are full, they should be sealed and stored in a private location. It is necessary to work with a licenced contractor you can trust, such as Initial Medical, who will safely and legally collect the waste and dispose of it in the correct manner. All Initial Medical technicians have undergone the required ADR training and they strive to always provide outstanding customer service.

Don't forget, if you or any member of your team has a question about safe and effective waste segregation and disposal, the experts at Initial Medical would be more than happy to help.

For further information visit www.initial.co.uk/medical.

\section{Save the date for the Digital Symposium}

Henry Schein Dental in collaboration with Dentsply Sirona are delighted to announce that the highly popular Digital Symposium is back, and this year the event promises to be bigger and better than ever.

Designed for all dental professionals wanting to expand their knowledge about how digital solutions can transform the treatment of restorative patients, the Digital Symposium will again be hosted at the impressive Grange St Paul's Hotel London on 5 and 6 May 2017.

The 6th annual Digital Symposium brings together a first-class speaker line-up, featuring many of the leading names in the world of digital dentistry. This year's speakers include Mervyn Druian, Monik Vasant, Uchenna Okoye and renowned technician Mark Ambridge.

Featuring two days of high quality lectures and hands-on workshops from digital experts at the top of their profession, the Digital Symposium is a must-attend event for everyone, from those just starting on their digital journey to the most experienced professionals who are already realising the many benefits of an integrated digital workflow.

Students can attend both days for just $£ 135$. (Student ID is required for verification.) Day passes are available for $£ 66$. Contact Henry Schein Dental for a day pass code for online booking. For more information or to register visit hsddigitalsymposium.co.uk, call 02072981980 or email hsddigitalsymposium@henryschein.co.uk.

\section{Added value training opportunities}

Providing added value to all its existing customers, Carestream Dental is offering various training opportunities from its Showroom in Stevenage.

The next courses are:

Understanding dental $\mathrm{X}$-ray technology and the need to minimise patient dose

Instructor: Ernesto Jaconelli

15 March 17:00 - 19:00

27 April 17:00 - 19:00

23 May 17:00 - 19:00

Boost your business with CS R4+ (the launch of Springboard V2) - hands-on training Instructor: Liam Rushton

28 March 17:00 - 20:00

\section{CS 3600 and CS 8100 3D user meeting}

Instructors: David Claridge and Rob Charteris

2 March 17:00 - 21:00

3 March 09:00 - 16:00

To find out more about any of these training opportunities, contact the friendly team at Carestream Dental on 08001699692 or visit www.carestreamdental.co.uk.

\section{It's time to get things done}

There can be few other professions that are as aware of time management as the general dental practitioner. We divide our working day into slots usually of around 15 minutes and are acutely aware of how even small variations in this use of time can have huge implications in how much or little we can get done in a session. We are as a result incredibly productive, having 30 or 40 contacts a day with people which can range from a conversation to emergency extractions.

Using this insight of the power of just 15 minutes, Quart is a productivity app developed by a GDP that approaches personal productivity in a revolutionary new way. It is a to-do list combined with a 15 minute timer. By linking a task with a fixed time to focus on it - a 'quart' - we can bring the productivity of the clinic to all aspects of our lives. It can also be a

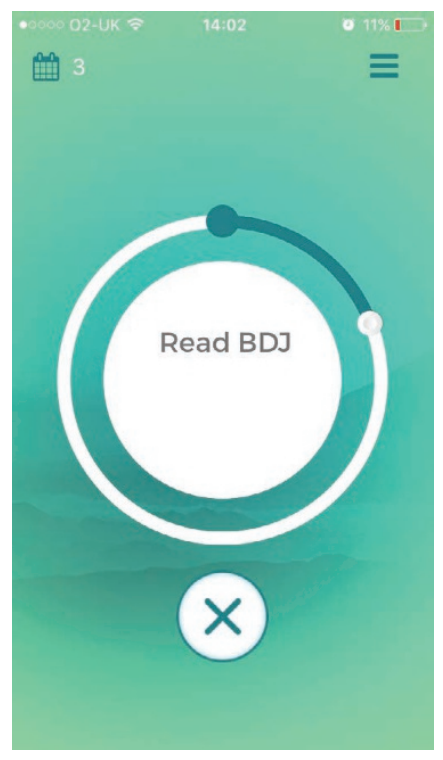
means to relax and take a quart to pause from a busy day. In a ceaseless digital world, quart is both the longer moment and the quicker hour we need. All the quarts completed are logged and stored so it is an effective way to record non-verifiable CPD.

Quart is available to be downloaded from the Apple App Store for 99p: https://appsto.re/gb/olWqhb.i

For more about Quart, your new productivity manager, visit www.quart.life. 